\title{
AUTOMATING SOFTWARE CODE DEPLOYMENT USING CONTINUOUS INTEGRATION AND CONTINUOUS DELIVERY PIPELINE FOR BUSINESS INTELLIGENCE SOLUTIONS
}

\author{
Farhana Sethi ${ }^{1}$ \\ ${ }^{1}$ Global Data \& Analytics Business Intelligence -Quality \& Governance
}

October 26, 2020

\section{Hosted file}

IJISRR-268.pdf available at https://authorea.com/users/358660/articles/489001-automatingsoftware-code-deployment-using-continuous-integration-and-continuous-delivery-pipelinefor-business-intelligence-solutions 